\title{
A ÁREA DA TRADUÇÃO NOS CURSOS DE LETRAS DA UNIVERSIDADE FEDERAL DE SANTA CATARINA
}

\author{
THE TRANSLATION FIELD IN FOREIGN LANGUAGE AND LITERATURE \\ COURSES AT THE FEDERAL UNIVERSITY OF SANTA CATARINA
}

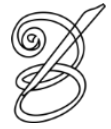 \\ Thaís Collet ${ }^{1}$ \\ (Doutoranda em Estudos da Tradução - Universidade Federal de Santa Catarina/Brasil) \\ thais_collet@hotmail.com \\ Ina Emmel ${ }^{2}$ \\ (Professora do Departamento de Línguas Estrangeiras - Universidade Federal de Santa Catarina/Brasil) \\ inaemmel@gmail.com
}

\begin{abstract}
Resumo: Este trabalho apresenta a análise dos resultados de uma pesquisa aplicada aos alunos de Letras (Alemão, Espanhol, Francês, Inglês e Italiano) da Universidade Federal de Santa Catarina (UFSC) que teve por objetivo (i) verificar se havia interessados pela área da Tradução e (ii) qual seria o perfil deles. 39 alunos que estavam concluindo a terceira e última disciplina obrigatória de Estudos da Tradução responderam a um questionário com questões objetivas. Antes de ingressar no curso, apenas 14 alunos tinham interesse em atuar como tradutor, mas após quatro semestres, este número dobrou, o que demonstra que as disciplinas de Estudos da Tradução, realizadas no curso de Letras, motivaram os alunos, ainda que eles pareçam desconhecer muitas das exigências da profissão.
\end{abstract}

Palavras-chave: Letras; Tradução; Perfil dos alunos.

Abstract: This paper shows an analysis of the results from a research done with undergraduate students of Foreign Language and Literature Courses (German, Spanish, French, English and Italian) at the Federal University of Santa Catarina (UFSC). 39 students, who were concluding the third and final compulsory discipline on Translation Studies, have participated of this research, which aimed to (i) identify whether there were students interested on Translation field and (ii) how could be their profile. Before starting the course, only 14 students were willing to work as a translator, but after four semesters, this number doubled, which shows that Translation Studies disciplines taught in the Language and Literature courses has motivated the students, yet they seem to be unaware of the many demands of the profession.

Keywords: Foreign Language and Literature undergraduate courses; Translation; Students' profiles.

\section{INTRODUÇÃO}

$\mathrm{E}$ ste trabalho apresenta a análise dos resultados de uma pesquisa realizada com alunos do curso de Letras da Universidade Federal de Santa Catarina (UFSC) com o intuito de verificar se (i), no atual curso, havia interessados pela área da Tradução e (ii) qual seria o perfil desses discentes. 
O curso de Letras da UFSC oferece habilitações em Licenciatura e Bacharelado em cinco línguas: Alemão, Espanhol, Francês, Inglês e Italiano. Ainda que a UFSC não tenha um curso de Bacharelado em Tradução, quem procurar pelos cursos de Letras no site da Universidade $^{3}$ encontrará a Tradução como uma das áreas de possível atuação do profissional formado em Letras:

O profissional formado nos Cursos de Língua e Literatura pode lecionar no ensino médio e fundamental, além de poder atuar em cursos pré-vestibulares e em escolas especializadas em idiomas. $\mathrm{O}$ campo de trabalho ainda abrange a área de intérprete de reuniões e conferências, a tradução de textos técnicos e literários, a revisão e preparação de textos e a pesquisa teórica da Literatura e da Linguística.

Em relação a isso, observa-se que países com tradição no ensino de Tradução já comprovaram por meio de suas experiências que há necessidade de uma formação específica em Tradução e que “[...] os estudos linguísticos, literários e filológicos, com objetivos e aproximações diferentes, não conseguiam formar tradutores e intérpretes profissionais" (ANECA, 2004, p. 15, tradução nossa) ${ }^{4}$.

144 A área da Tradução é contemplada, no atual currículo do curso de Letras da UFSC (que foi introduzido em sua presente configuração no primeiro semestre de 2007), com três disciplinas obrigatórias em Estudos da Tradução que somam 144 horas: "Introdução aos Estudos da Tradução" (36h) $)^{5}$, "Estudos da Tradução I" (72h) ${ }^{6}$ e "Estudos da Tradução II" $(36 \mathrm{~h})^{7}$. Essas disciplinas são ministradas em português e fazem parte do núcleo comum, isto é, alunos de cursos de Letras diferentes têm aulas conjuntamente, ou seja, na mesma aula poderá haver alunos do curso de Letras Alemão, Inglês, Espanhol, Italiano e/ou Francês.

Além das disciplinas obrigatórias, aos alunos também são exigidas 180 horas de disciplinas optativas, na habilitação em Licenciatura, ou 360 horas, na habilitação em Bacharelado, que poderiam ser cumpridas integralmente na área de Tradução, se esta fosse a escolha do aluno, observando, claro, que a oferta destas disciplinas é bastante irregular, ou seja, não são oferecidas todo semestre e/ou ano.

Entre as disciplinas optativas na área da Tradução ${ }^{8}$, há, por exemplo, no curso de Letras Alemão: “Tópico especial em Tradução do/para o Alemão” (72h), “Tópico Especial em Tradução I" (36h), "Estudos da Tradução em Alemão I" (36h) e "Estudos da Tradução em Alemão II" (72h), "Tradução técnica e oficial (72h)", "Tradução jornalística” (72h), "Tradução literária comentada" (72h) e "Literatura Alemã em Tradução" (72h); no curso de Inglês: “Tópico especial em Tradução” (36h), "Estudos da Tradução - Revisão e preparação 
de texto" (36h) e "Estudos da Tradução: Laboratório de Tradução" (72h), "Estudos da Tradução em Inglês I" (36h) e "Estudos da Tradução em inglês II" (72h).

Os alunos que optam pelo bacharelado devem escrever um Trabalho de Conclusão de curso $(\mathrm{TCC})^{9}$. A Tradução representa um número relevante nos TCCs em comparação com as áreas da Linguística e Literatura dentro do curso de Letras da UFSC em sua atual configuração. Por meio dos trabalhos listados na página do Departamento de Línguas Estrangeiras ${ }^{10}$, constatou-se que dos 67 trabalhos defendidos, 26 eram da área da Tradução ${ }^{11}$, o que representa $38 \%$ do total dos trabalhos. ${ }^{12}$

Apesar de a UFSC ter programa de mestrado e doutorado na área da Tradução (Pósgraduação em Estudos da Tradução - PGET), está em processo de abertura de um curso de Bacharelado em Tradução; e, assim, a Tradução deixaria de ser apenas uma mera possibilidade de atuação do egresso em Letras. Kelly (2005) afirma que um dos itens a serem considerados para o processo do desenho curricular de qualquer curso é o perfil dos alunos. Para a autora, desenho curricular é o "[...] processo pelo qual são planejados os objetivos gerais, a estrutura do curso, as atividades, a sequência e as avaliações"13 (2005, p. 158,

tradução nossa). Kelly (2010) cita como alguns dos itens essenciais a serem analisados no perfil: conhecimento prévio, características pessoais, estilos e enfoques de aprendizagem, expectativas e motivações e grau de homogeneidade. Embora esta pesquisa não cubra todos estes itens, os resultados nela obtidos, poderiam, de certa forma, se constituir em um dado adicional para o desenho curricular do Bacharelado em Tradução na UFSC.

\section{A PESQUISA}

A pesquisa foi realizada em sala de aula, com a anuência do respectivo professor da disciplina, no final do segundo semestre de 2012, com os alunos de Letras (Alemão, Espanhol, Francês, Inglês e Italiano), matriculados na disciplina de "Estudos da Tradução II", e, portanto, concluindo a terceira disciplina obrigatória da área. A pesquisa foi realizada por meio de um questionário ${ }^{14}$ que constava de duas partes: a primeira com cinco questões objetivas de múltipla escolha; e a segunda, deveria ser respondida caso tivessem interesse em atuar como tradutor, e continha 20 sentenças de verdadeiro ou falso. A segunda parte é uma tradução de um teste proposto por Gouadec (2010, p. 160-161) para interessados na área se autoavaliarem em relação a ter ou não o perfil requisitado. $\mathrm{O}$ autor, que tem várias publicações na área e lecionou disciplinas de $\operatorname{Tradução}^{15}$, afirma que este seria um teste 
simples para qualquer interessado em atuar na área para verificar se possui (ou não) o perfil do profissional.

Abaixo, apresentam-se os resultados da pesquisa que teve 39 alunos como participantes.

A questão "A" buscava verificar se os alunos cursavam Licenciatura ou Bacharelado. A maioria, 21 alunos, afirmou cursar Licenciatura, 12 o Bacharelado e seis informaram que pretendiam terminar ambos (Licenciatura e Bacharelado), como é possível verificar no Gráfico 1:

Gráfico 1 - Resultado da questão A - Sou aluno de Letras

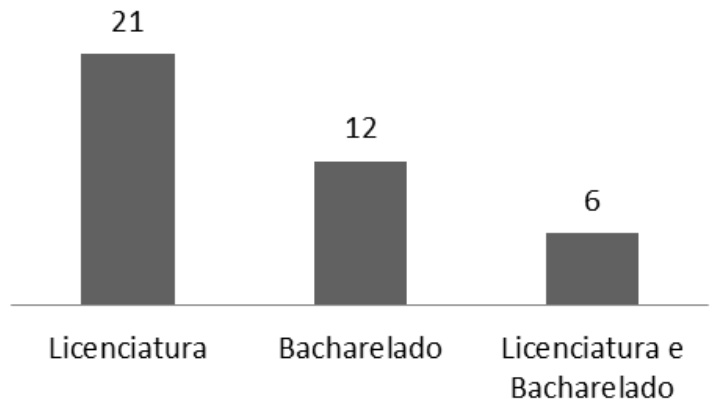

Fonte: Elaborado pelas autoras.

A questão "B" visava verificar o objetivo do aluno ao entrar no curso. No Gráfico 2 abaixo, observa-se que o objetivo inicial da maioria, 21 alunos, era atuar como professor, o que justifica a escolha pela Licenciatura. Um número bastante representativo, 14, afirmou que tinha como intenção atuar como tradutor; oito afirmaram que o objetivo inicial era atuar como pesquisador; quatro informaram que cursavam apenas para aprender língua estrangeira e um afirmou que seu objetivo era dar aulas particulares ou atuar na área de turismo. Atenta-se para o fato de que alguns alunos marcaram mais de uma opção, e, por isso, o número de respostas é superior ao número de participantes. 
Gráfico 2 - Resultado da questão B - Meu principal objetivo ao escolher este curso era

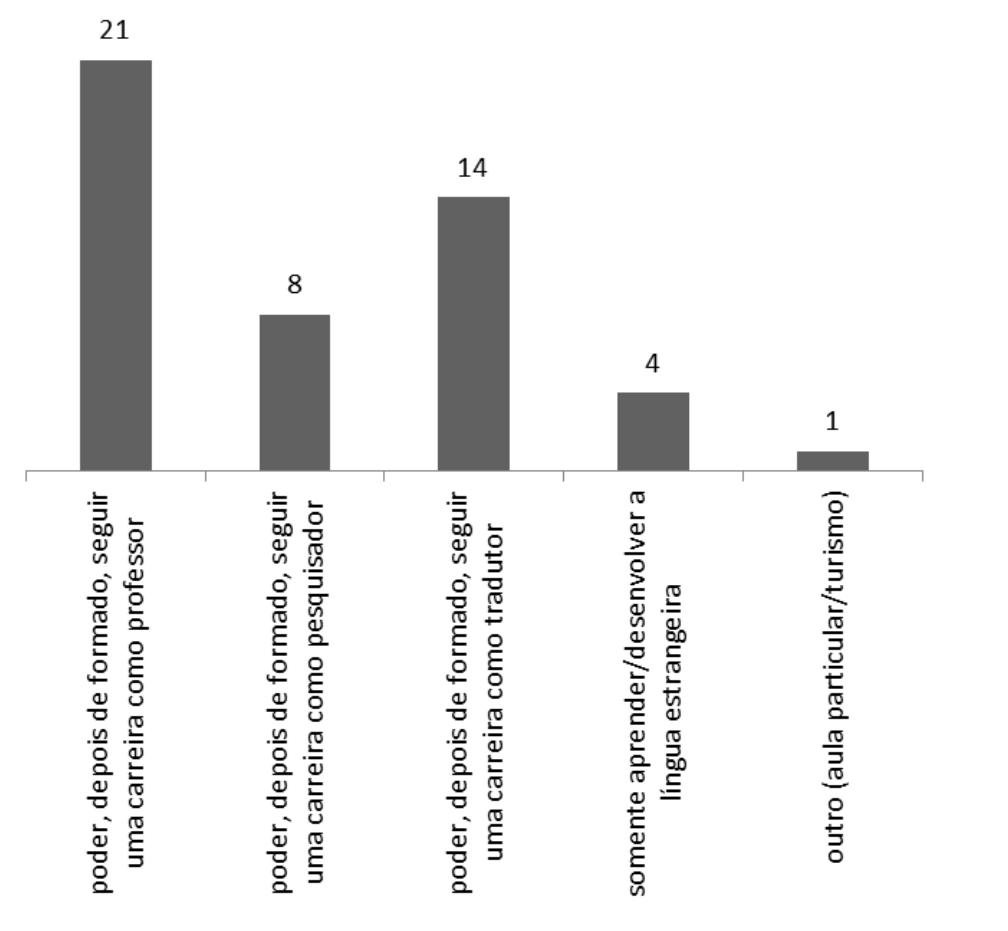

Fonte: Elaborado pelas autoras.

No Gráfico 3 abaixo, apresentam-se os resultados da questão "C", que questionava sobre a atuação como tradutor antes de entrar no curso: 29 dos 39 respondentes afirmaram que não atuavam previamente como tradutores, oito que sim, mas não profissionalmente (sem remuneração) e apenas dois que sim, atuavam já na área:

Gráfico 3 - Resultado da questão C - Você já traduzia antes de entrar para o curso?

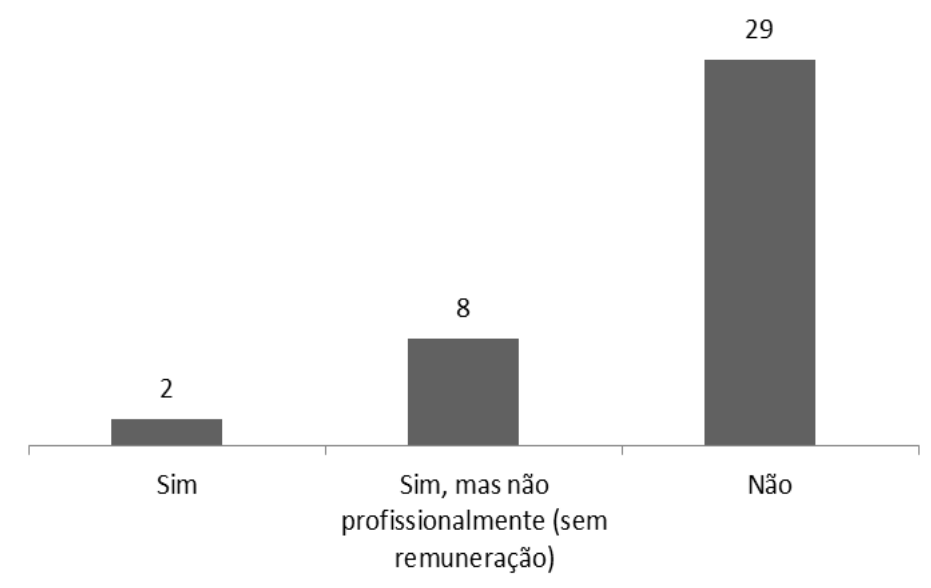

Fonte: Elaborado pelas autoras. 
Já a questão "D”, procurava verificar a atual atuação na área, na tentativa de comparar com a atuação anterior a entrar no curso, como resultado, então, após quatro semestres, apenas um (01) aluno passou a traduzir recebendo remuneração. Dezesseis (16) afirmaram que traduzem sem receber remuneração e dezenove (19) afirmaram que não traduziam, como pode ser visto no Gráfico 4:

Gráfico 4 - Resultado da questão D - Atualmente, você traduz?

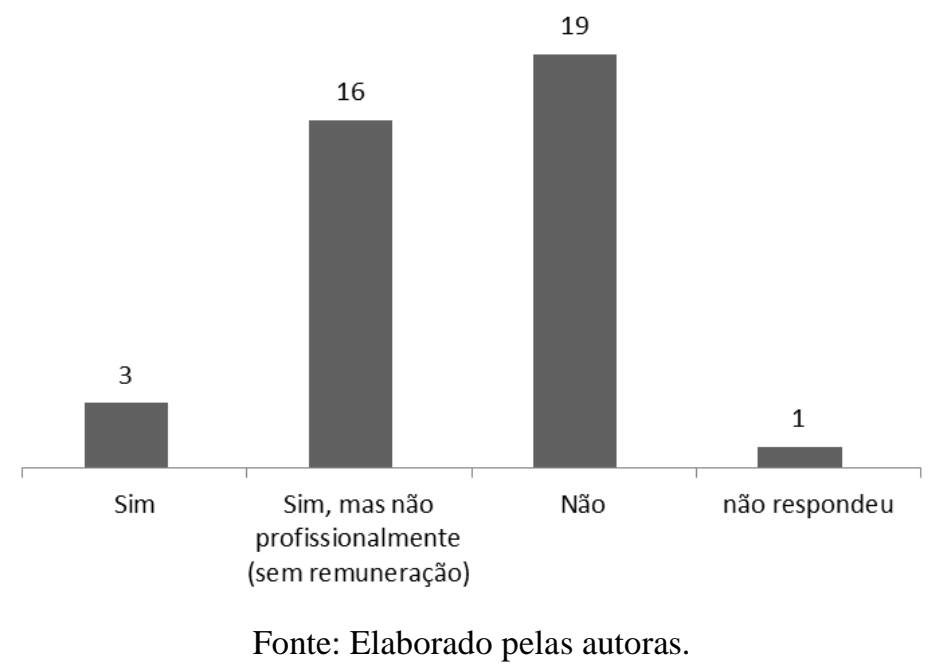

A questão E (Gráfico 5 abaixo), também com o intuito de fazer uma comparação, questionou sobre o interesse de atuar na área: quatorze (14) tinham respondido que tinham como objetivo, ao entrar no curso, trabalhar como tradutor (Gráfico 2) e agora vinte e oito (28) afirmaram ter interesse na área, ou seja, o número dobrou, o que indica que muitos acabaram se interessando por esta área no decorrer do curso. Apenas onze (11) responderam não ter interesse em atuar na área, como pode ser visto no Gráfico 5: 
Gráfico 5 - Resultado da questão E - Depois de formado, você gostaria de/pensa em traduzir?

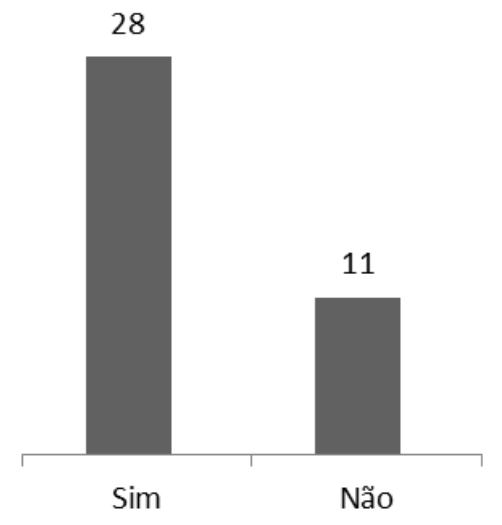

Fonte: Elaborado pelas autoras.

Esse resultado se justifica pelo fato de que muitos já tinham traçado como objetivo atuarem com professor de língua provavelmente em função de afinidades com a profissão. Mas o fato de muitos terem alterado a visão pode ter sido consequência das três disciplinas cursadas que abriu um leque de opções de atuação não inicialmente vislumbradas.

É necessário observar, no entanto, que talvez trinta e nove (39) respondentes não seja um dado significativo, considerando que entram a cada ano no curso de Letras em suas dez (10) habilitações duzentos (200) alunos, ou seja, a evasão é alta, e, assim, outro tipo de instrumento para verificar estas questões talvez pudesse controlar melhor as variáveis.

A segunda parte, constante de 20 questões de verdadeiro ou falso (GOUADEC, 2010, p. 161) foi respondida apenas por aqueles que afirmavam ter como objetivo trabalhar com tradução, ou seja, vinte e oito (28) alunos.

A seguir, no Quadro 1, apresentam-se os resultados: 
Quadro 1. Levantamento com os alunos de Letras interessados em atuar como tradutor - resultados

\begin{tabular}{|c|c|c|c|}
\hline \multirow{2}{*}{ Marque V se a questão for verdadeira para você e F, se ela for falsa. } & & & \\
\hline & $\mathrm{V}$ & $\mathrm{F}$ & $\begin{array}{c}\text { Em } \\
\text { branco }\end{array}$ \\
\hline 1. Sempre quis traduzir. & 6 & 12 & 10 \\
\hline 2. Gosto de tudo que se refira à tecnologia de informação. & 8 & 20 & \\
\hline 3. Nunca desisto: continuo tentando até achar a resposta. & 21 & 7 & \\
\hline 4. Em casa, estou sempre envolvido/ocupado com alguma coisa tecnológica. & 17 & 11 & \\
\hline 5. Posso lidar com estresse e trabalhar sob pressão. & 17 & 11 & \\
\hline 6. Sou muito organizado e meticuloso. & 14 & 14 & \\
\hline $\begin{array}{l}\text { 7. Não desistiria da profissão mesmo que tivesse que trabalhar } 14 \text { horas por } \\
\text { dia. }\end{array}$ & 13 & 15 & \\
\hline 8. Gosto de trabalhar em equipes (de participar e liderar). & 17 & 9 & 2 \\
\hline 9. Sei receber críticas a respeito do meu trabalho. & 28 & 0 & \\
\hline 10. A web é meu lar virtual. & 11 & 16 & 1 \\
\hline 11. Sou bom no improviso e sem medo de me arriscar. & 15 & 13 & \\
\hline 12. Não me importo de ter que trabalhar em feriados. & 16 & 11 & 1 \\
\hline 13. Posso me adaptar em qualquer lugar. & 22 & 5 & 1 \\
\hline 14. Sou muito curioso para aprender como tudo funciona. & 22 & 6 & \\
\hline 15. Sou perfeccionista. & 18 & 10 & \\
\hline $\begin{array}{l}\text { 16. Estou pronto para mudar meus planos em um curto período de tempo, se } \\
\text { necessário. }\end{array}$ & 24 & 4 & \\
\hline $\begin{array}{l}\text { 17. Gosto de interagir com outras pessoas, mesmo quando a situação fica um } \\
\text { pouco tensa. }\end{array}$ & 18 & 9 & 1 \\
\hline 18. Gosto de trabalhar em algo que seja sempre desafiador. & 21 & 6 & 1 \\
\hline 19. Não me importo de traduzir documentos repetitivos ou comuns. & 23 & 5 & \\
\hline 20. Eu amo línguas estrangeiras. & 26 & 2 & \\
\hline
\end{tabular}

Fonte: Elaborado pelas autoras a partir do questionário traduzido de Gouadec (2010, p. 161) e com resultados obtidos na pesquisa pelas autoras. ${ }^{16}$

Gouadec (2010), em relação a este teste (proposto por ele com o objetivo de os alunos de autoavaliarem e refletirem sobre as exigências da profissão), afirma que, considerando a carreira de tradutor, o respondente que marcasse as vinte (20) questões verdadeiras teria definitivamente potencial para ser um bom tradutor profissional (e o melhor seria se as prioridades estivessem nesta ordem). Se marcasse uma (01) falsa (nas dez (10) primeiras questões), as coisas estariam indo bem, duas (02) falsas (nas dez (10) primeiras frases), o respondente deveria pensar mais um pouco a respeito e, caso marcasse três (03) falsas (nas 
dez (10) primeiras), a tradução não seria a sua especialidade, nem profissionalmente, nem pessoalmente. No Gráfico 6 são apresentados os resultados em relação ao número de questões marcadas verdadeiras ou falsas.

Gráfico 6- Resultado final do questionário

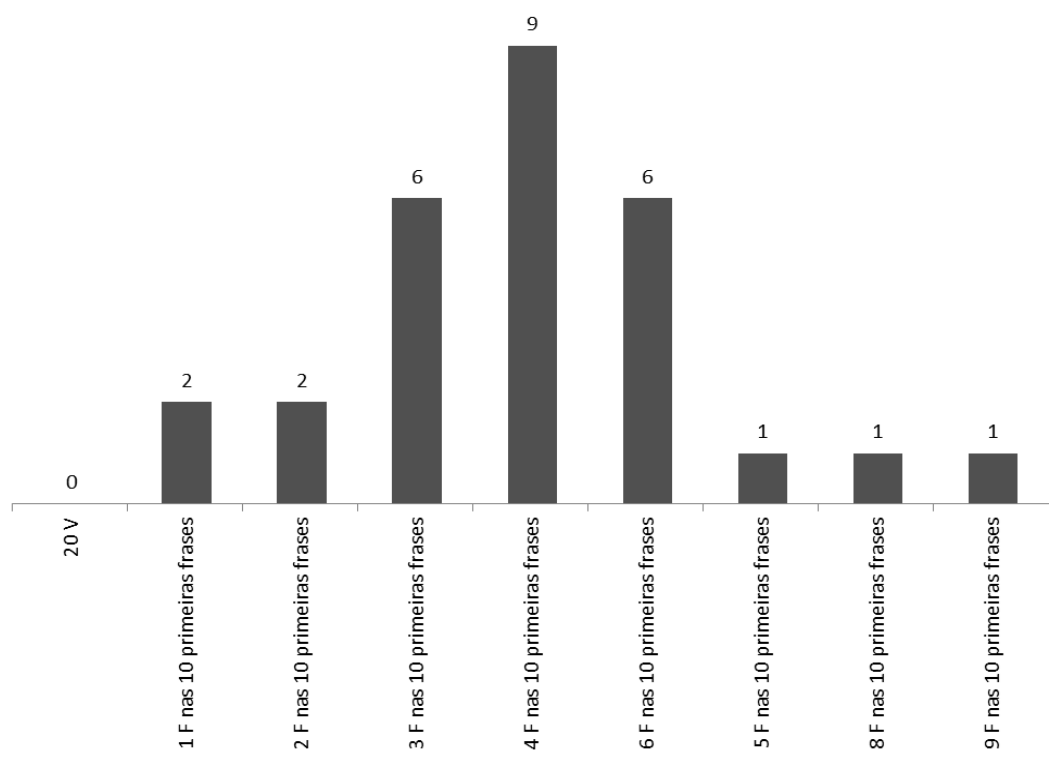

Fonte: Elaborado pelas autoras.

Analisando os resultados em relação às observações do autor, nenhum dos alunos teria o perfil para ser tradutor e a maioria estaria bem longe disso. As questões de Gouadec (2010) parecerem ser um tanto extremistas (comentário feito pelos próprios alunos ao responderem ao questionário) e se reconhece neste trabalho que o teste proposto pelo autor é, em sua essência, tendencioso e talvez não seja o mais apropriado para realmente avaliar o perfil de um candidato. Porém, acredita-se que Gouadec, que tem grande experiência, coloca desta forma para justamente o interessado refletir sobre as exigências da área (que não são poucas). E ainda que o teste tenha sido elaborado por um professor em uma realidade francesa, as exigências listadas nele se aplicam também ao mercado brasileiro.

\section{CONSIDERAÇÕES FINAIS}

Com os dados obtidos no questionário, é possível verificar que alunos entram no curso de Letras da UFSC interessados pela área da Tradução e que houve um aumento deste interesse após cursarem as disciplinas obrigatórias em Estudos da Tradução, então, acredita-se 
que os alunos seguirão fazendo disciplinas optativas na área da Tradução se estas forem oferecidas. Porém, apesar do interesse, os alunos parecem desconhecer a realidade de atuação que exige interesse pelas tecnologias e pela web (SAMSON, 2005; GOUADEC, 2010, BOWKER; FISCHER, 2010; MACKENZIE, 2004), trabalhar muitas vezes horas extras para terminar um projeto, ter habilidade interpessoal (o trabalho do tradutor não se resume mais a uma tarefa solitária), organização e persistência (MACKENZIE, 2004; GOUADEC, 2010), etc. Isso talvez seja reflexo do conhecimento adquirido nas disciplinas de Estudos da Tradução que é, em grande parte, basicamente teórico.

\section{REFERÊNCIAS BIBLIOGRÁFICAS}

ANECA. Agencia Nacional de Evaluación de la calidad y acreditación. Libro Blanco: Título de Grado en Traducción e interpretación. 2004. 146 p. Disponível em: http://www.aneca.es/var/media/150288/libroblanco_traduc_def.pdf Acesso em: 20 mai 2012.

BOWKER, Lynne; FISCHER, Des. Computer Aided translation. In: GAMBIER, Yves; VAN DOORSLAER, Luc (eds). Handbook of Translation Studies. Amsterdam/Philadelphia: John Benjamins, 2005. p. 60-65.

GOUADEC, Daniel. Translation as a Profession. 2a ed. revisada. Amsterdam/Philadelphia: John Benjamins Publishing Company, 2010. 409 p.

KELLY, Dorothy. A Handbook for Translator trainers. Manchester: St. Jerome, 2005. $173 p$.

KELLY, Dorothy. Curriculum. In: GAMBIER, Yves; VAN DOORSLAER, Luc (Eds). Handbook of Translation Studies. V. 1. Amsterdam: John Benjamins, 2010. p. 87-93.

MACKENZIE, Rosemary. The competencies required by the translator's roles as a professional. In: MALMKJAER, Kirsten. Translation in undergraduate degree programmes. Amsterdan: John Benjamins, 2004. p. 31-38.

SAMSON, Richard. Computer-assisted translation. In: TENNENT, Martha (Ed). Training for the new millenium. Amsterdam/Philadelphia: John Benjamins, 2005. p. 101-126.

UFSC. Coordenadoria do Curso de Letras - Línguas estrangeiras. Estrutura do curso. Disponível em: http://cagr.sistemas.ufsc.br/arvore.xhtml?treeid=0. Acesso em 15 abril 2013.

UFSC. Departamento de Línguas Estrangeiras. Currículos, ementas e TCCs. Disponível em: http://www.lle.cce.ufsc.br/index.php>. Acesso em 27 set. 2014. 
ANEXO A - QUESTIONÁRIO DE DANIEL GOUADEC (2010, p. 161)

\begin{tabular}{l|c|c|}
\hline$N^{\circ}$ Statements & True & False \\
\hline 1. Translation is something I have always wanted to do. & \\
2. I am really into anything to do with information technology. & \\
3. I never give up: I keep trying until I find the answer. & \\
4. I am at home with anything technical. & \\
5. I can cope with stress and working under pressure. & \\
6. I am very well organised and very meticulous. & \\
7. Having to work 14 hours a day would not put me off. & \\
8. I feel happy working in teams; I love the give and take of teamwork. & \\
9. I can put up with critical appraisal of my work. & \\
10. The Web is my virtual home. & \\
11. I'm good at improvising and I'm not adverse to risk. & \\
12. I don't mind giving up part of my holidays. & \\
13. I can adapt anywhere. & \\
14. I'm always curious to find out how things work. & \\
15. I'm a perfectionist. & \\
16. I'm ready to change my plans at short notice. & \\
17. I like interacting with other people, even when things get a bit tense. & \\
18. I want to do a job that is constantly challenging. & \\
19. I don't mind translating repetitive or run-of-the-mill documents. & \\
20. I love foreign languages. &
\end{tabular}

\section{Results:}

20 'true': you have definitely got what it takes to be a good professional translator and all the better if your priorities are in that order!

1 'false' in the first ten statements: things are looking good.

2 'false' in the first ten statements: have another think about it.

3 'false' in the first ten statements: professional translation is probably not your cup of tea, either professionally speaking, or on a personal level.

RECEBIDO EM 18/12/2014

ACEITO EM 12/01/2015

\footnotetext{
${ }^{1}$ Lattes - Thaís Collet. Disponível em: http://lattes.cnpq.br/6760166932000024. Acesso: jan. 2015.

${ }^{2}$ Lattes - Ina Emmel. Disponível em: http://buscatextual.cnpq.br/buscatextual/visualizacv.do?id=K4777821H6.

${ }^{3}$ Disponível em: http://cagr.sistemas.ufsc.br/arvore.xhtml?treeid=0>. Acesso em: 15 abril 2013.

4 “[...] los estudios lingüísticos, literarios y filológicos, con objetivos y aproximaciones distintos, no alcanzaban a formar traductores e intérpretes profesionales."
} 
${ }^{5}$ Ementa da disciplina Introdução aos Estudos da Tradução (Como são disciplinas do núcleo comum, as ementas são as mesmas para todos os cursos de Letras da UFSC.): “Conceitos e conscientização dos problemas teóricos e práticos da tradução.” Disponível em: http://www.lle.cce.ufsc.br/xalemao/programas/LLE7030.pdf.>. Acesso em: 08 dez. 2014.

${ }^{6}$ Ementa da disciplina Estudos da Tradução I: "História da tradução e das teorias da tradução. Estudo diacrônico e sincrônico da atividade tradutória. Concepção da tradução, papel e prática do tradutor. Situação dos textos traduzidos em diferentes países e momentos históricos". Disponível em: http://www.lle.cce.ufsc.br/xalemao/programas/LLE7031.pdf. Acesso em: 08 dez. 2014.

${ }^{7}$ Ementa da disciplina Estudos da Tradução II: “Teorias da tradução. Estudo e prática de tradução. Elementos constitutivos das teorias da tradução. Diferentes concepções e teorizações. Aplicação de modelos teóricos e de estratégias de tradução”. Disponível em: http://www.lle.cce.ufsc.br/xalemao/programas/LLE7032.pdf. Acesso em: 08 dez. 2014.

8 As disciplinas optativas podem ser vistas nos currículos de cada curso. Disponível em: http://www.lle.cce.ufsc.br/index.php\#>. Acesso em: 13 set. 2014.

${ }^{9}$ Os alunos de Letras que optam por fazer Licenciatura realizam um estágio e apresentam um relatório, não escrevendo, portanto, um trabalho de conclusão de curso (TCC).

${ }^{10}$ Os trabalhos listados datam de 2010 a 2014. A lista dos trabalhos realizados em cada curso está disponível em: < http://www.lle.cce.ufsc.br/index.php>. Acesso em: 27 set. 2014.

${ }^{11}$ A área foi constatada através do título e palavras-chave.

${ }^{12}$ No site do curso de Letras Inglês, havia vinte e um (21) trabalhos de conclusão de curso listados e destes sete (07) eram na área da Tradução. No curso de Letras Alemão, havia dez (10) trabalhos, dos quais quatro (04) em Tradução. No curso de Letras Espanhol havia dezessete (17) trabalhos, dos quais seis (06) eram em Tradução. No curso de Letras Francês, havia onze (11) trabalhos, dos quais seis (06) em Tradução. E no curso de Letras Italiano havia oito (08) trabalhos, destes três (03) em Tradução.

13 “[...] process whereby overall intended outcomes, programme structure, activities, sequence and assessment are designed."

14 Antes de responderem ao questionário, os alunos foram informados a respeito da pesquisa e receberam e assinaram o termo de compromisso. Os respondentes receberam um certificado de participação em pesquisa para poder contar como Atividades acadêmico-científico-culturais (ACCs).

15 Daniel Gouadec foi professor da Université de Rennes 2, na França, e, antes de se aposentar em 2010, lecionou disciplinas como Gestão de Projetos de Tradução, Técnicas de Tradução, Terminologia, Terminografia, Tradução Técnica, Tradução Literária, Revisão, entre muitas outras. Também atuou como revisor, tradutor e publicou obras na área de Tradução e Terminologia. Informações retiradas do site pessoal do autor, disponível em: <http://www.gouadec.net/indexDG.html>. Acesso em: 13 abril 2013.

${ }^{16} \mathrm{O}$ questionário original encontra-se disponível no Anexo A. 